\title{
QUALITY FUNCTION DEPLOYMENT (QFD) PROCESSES IN AN INTEGRATED QUALITY INFORMATION SYSTEM
}

\author{
Chia-hao Chang \\ Department of Industrial \& Systems Engineering \\ University of Michigan-Dearborn
}

\begin{abstract}
A general design of an integrated total quality information system involving the Quality Function Deployment process is proposed in this paper. Data flow diagram is used to illustrate the structure of the information system. Within it, the Quality Function Deployment process is especially discussed in detail.
\end{abstract}

\section{BACKGROUND}

In recent years, companies in the U.S., big or small, are faced with keen competitions both at home and from abroad. Product defect free alone is not enough to guarantee customer satisfaction and stay competitive. More and more customers are looking for products that are tailored to their needs and preference. To assure that a product will be well accepted by customers, industries have to identify the customer requirements, convert them into finished product quality characteristics, and deploy those quality characteristics into process operations and production planning.

A quality information system to serve the aforementioned purpose can be used to monitor production performance, to prevent defects, and more important, to recognize the customers' perception of product quality. Those factors will lead to better performance, better products, better service, and eventually, better sales. The significance of such an information system to our industries' competitive edge is obvious. But none of the existing manufacturing control systems comprehensively fulfills that need (Suresh an Meredith, 1985).

\section{TOTAL OUALITY INFORMATION SYSTEM}

To fill the gap, a general design of a total quality information system is proposed. It will cover activities from the marketing phase, where customer needs and competitors' strategies are studied, through the preproduction design and planning, and quality control during the operations, to the postproduction service and follow-up activities where feedback is collected to determine the level of customer satisfaction.

Roughly such a system can be divided into three stages: preproduction, production and postproduction stages.

\section{Preproduction Stage and OFD Process}

The preproduction quality function has lately drawn a lot of attention from the quality control industries. One reason is that most companies are starting to recognize the importance of customer satisfaction to their sales. A process called Quality Function Deployment (QFD), formally adopted by some Japanese industries more than fifteen years ago, is used to direct the companies' planning and design by the customer needs (or the voice of the customer). Following QFD process, ill-defined or incomplete customer-requirements are converted into counterpart characteristics that determine the design quality of the product.

\section{Marketing study and product planning}

The process starts with marketing study which generally involves sales and market research. Market research is tasked with collecting the voice of the customer, which may take any of the following forms: primary customer wants and expectations.

At the same time, competitor information from market surveys, industry publications, etc. are also gathered. Market research analyzes primary customer wants, expectations, and opinions as well as information on common complaints and claims in coming up with secondary or even tertiary level quality requirements. These are requirements that are specific enough to define actual design qualities in the product. If actual customer specifications 
are available, these are also included. At the same time, competitor products' information is also analyzed to help identify the performance features of these products.

Secondary or tertiary requirements, specific customer specifications, and competitor products' performance are then matched and combined in order to identify specific product quality features which are controllable in the manufacturer's viewpoint. Furthermore, competitive benchmarks are analyzed in order to assist the deployment of specific target values later in the product design.

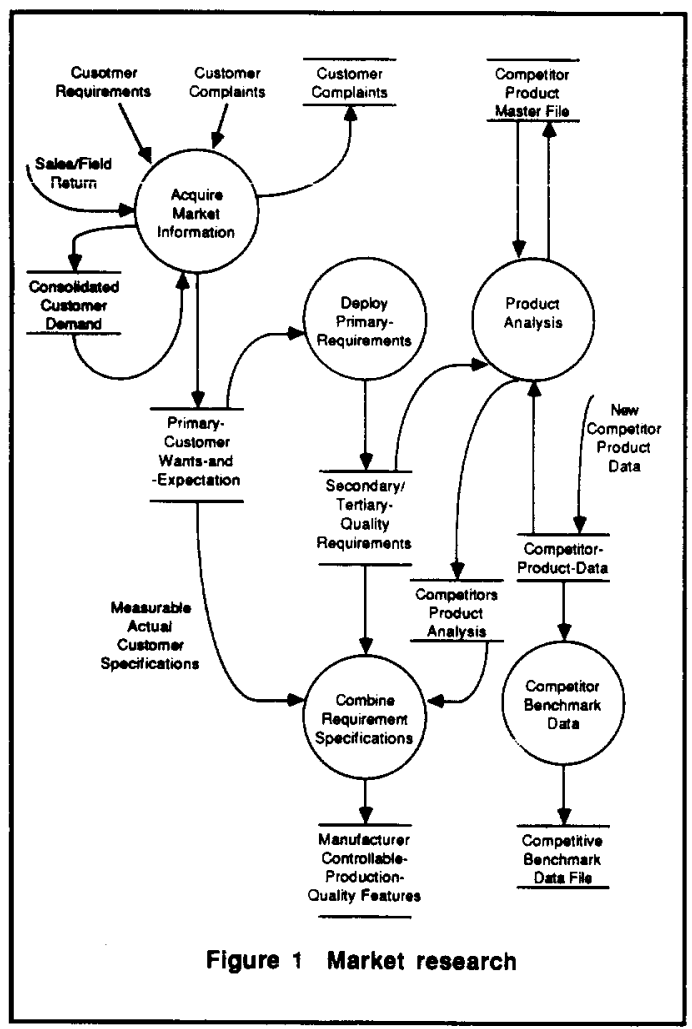

In as much as sales function is in direct communication with the customers of the company, product complaints, customer claims, design-betterment suggestions, and user murmurs are more easily transmitted to this department than any other in the company. All these customer inputs are analyzed in generating desired engineering changes to improve product quality. Failure-related complaints and returns are forwarded to the reliability laboratory for analysis and evaluation. All product failures and causes are recorded.

In the product design process, counterpart characteristics are generated based on the customer-specified quality features. On the basis of these counterpart characteristics, strength relations are identified between "wants" and "quality features". Also, relationships between the different quality features themselves are defined. Want-Quality relationships are analyzed to identify critical points for superior design as well as failure. With the help of a historical record of previous failures maintained by the sales and reliability lab departments, critical failure points are highlighted in a Failure Mode and Effects Analysis and are then maintained in a Failure Mode log for further product deployment. The Failure Mode and Effects Analysis is utilized in the recommendation of corrective actions for later inclusion in desired engineering changes. On the other hand, critical points for superior performance are emphasized, and along with competitive benchmark information, are deployed into specific quality target values to achieve best-in-class status. These target values, together with the results of the failure analysis and technical control items identified based on technological, legal, and government-mandated requirements are incorporated and further deployed into preliminary product quality features that are submitted for review and approval. Approved quality characteristics are then finalized for deployment into hardware components.

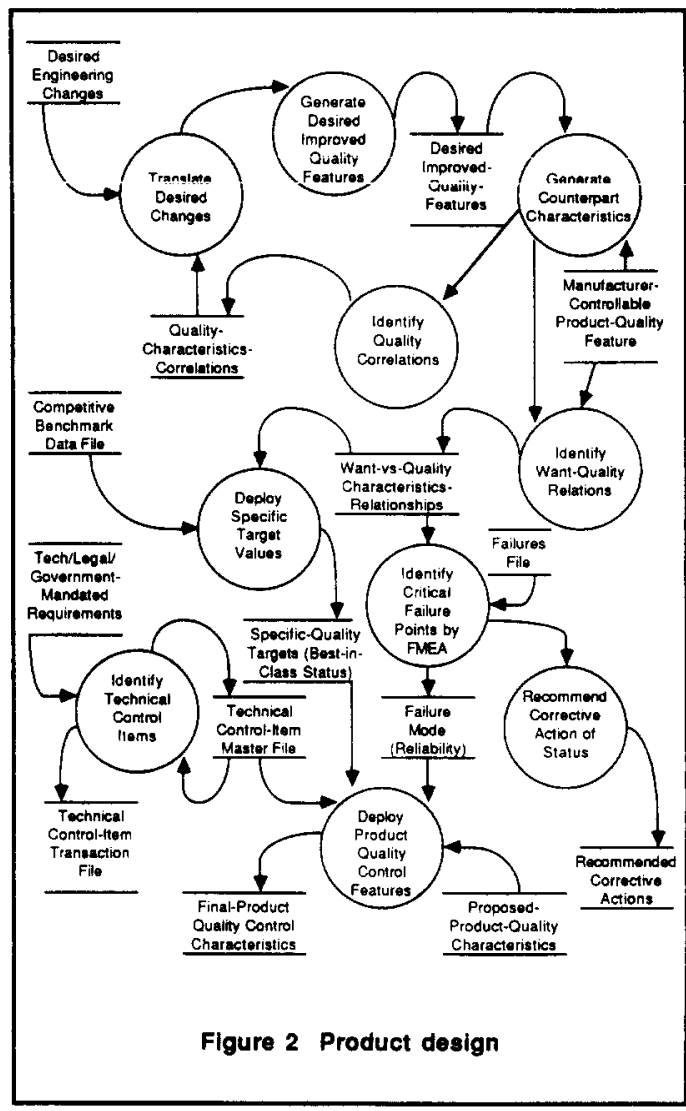




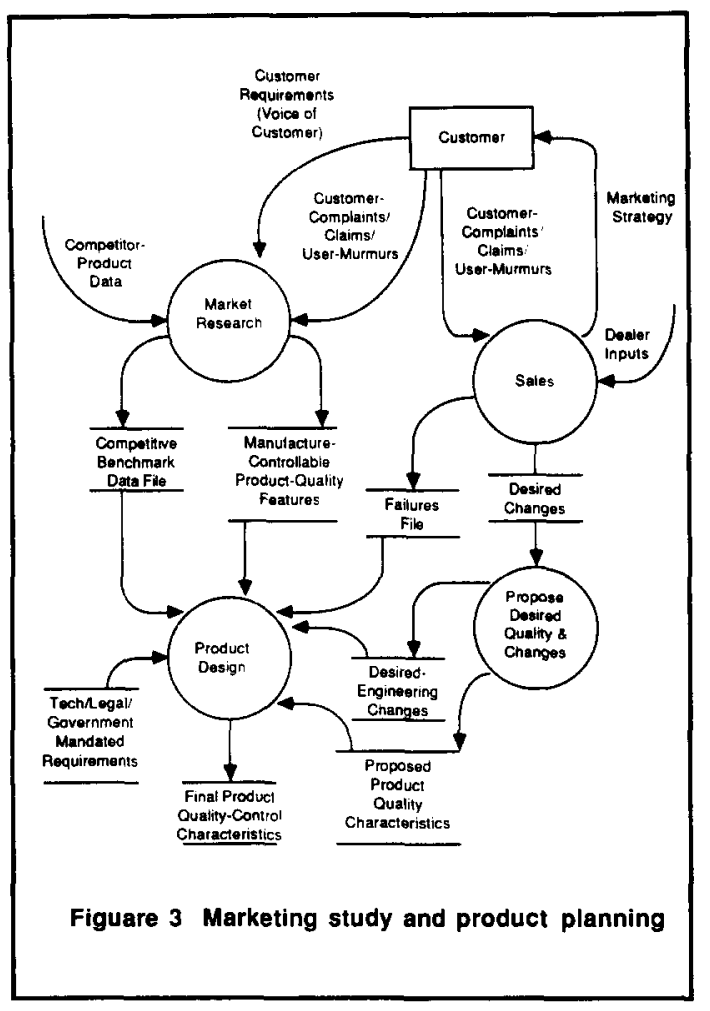

\section{ii. Part/mechanism deployment}

Part/mechanism deployment involves converting the final product quality characteristics into material parts and their functions. Based on the detail counterpart characteristics from product design, product component parts are selected and their respective functions are defined. Furthermore, reliability and cost estimates of these component parts are calculated and for less-than-optimum figures, upgrade goals are defined.

A new relationship matrix is then developed between the hardware components and the customer-specified wants, i.e., specific customer wants or requirements are matched with the component part(s) directly linked with the fulfillment of these wants. Some components may be more critical than others in satisfying customer requirements. In this case, these component parts are identified and called "critical". Critical components and their characteristics are carefully defined in a hardware deployment plan which is inspected against an updated Failure Mode and Effects Analysis. This hardware plan is then deployed, with reference to detailed quality target values, into critical component part characteristics which are then used as input to the process development and quality control planning activities.

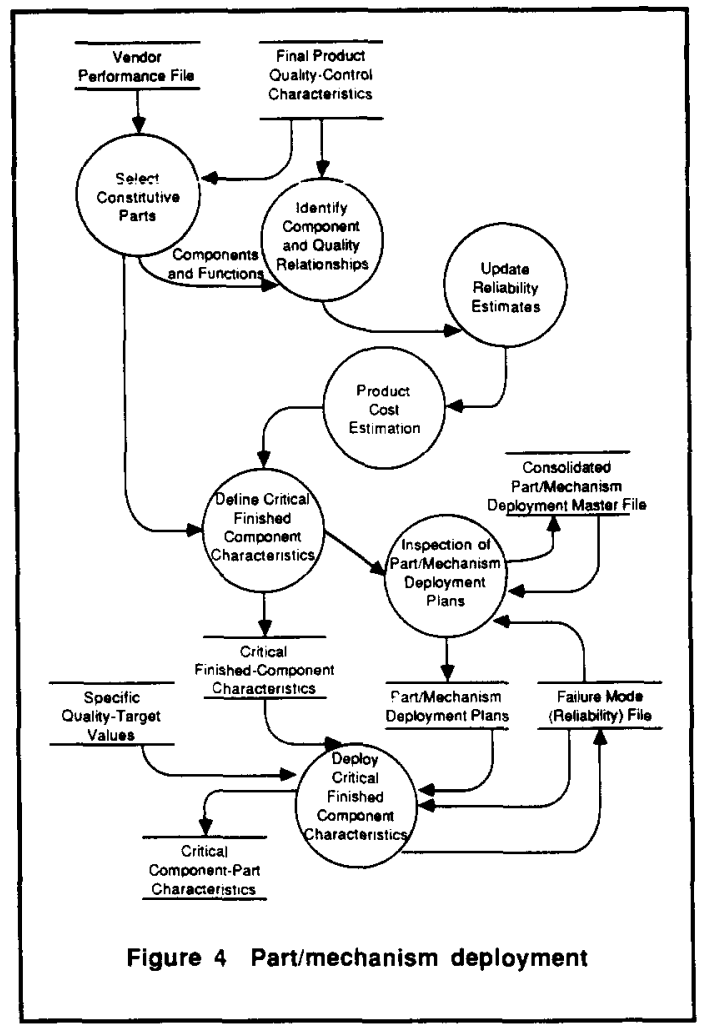

\section{iii. Process development and quality control planning}

Critical component parts and their characteristics from the previous stage are further deployed in process planning by first identifying the relationships between the component parts and their respective process operations. At this point, the respective processes to be performed on each of the hardware components are identified and defined for each part. At the same time, the strength of the relationships is emphasized in order to focus on the most critical processes and component parts.

Once the part and process relationships are defined, these are then used as inputs for the quality control planning activity in which both control and check points are identified. Control points are critical product component parameters (e.g. diameter, viscosity, surface finish, etc.) that are created or are directly affected in a given step or process. On the other hand, check points are critical process parameters (e.g. time, temperature, pressure, etc.) that must be monitored to assure that the component parameters are achieved. In process planning, these points are specifically described with considerable emphasis on the most critical ones. These are then used in quality planning for the 
preparation of the control and check plans. In these plans, check methods, sampling sizes, and check frequencies are detailed and eventually form the basis of the quality control plan that goes into the plant operating instruction set.

Aside from the control points identified for the critical component parts, a Failure Mode and Effects Analysis (FMEA) for the process is developed in order to determine methods of preventing both part and process types of failures. This is performed with reference to the Failure Mode or Reliability File created from the other FMEAs in the preceding stages. These methods are also incorporated into the design of the control plan.

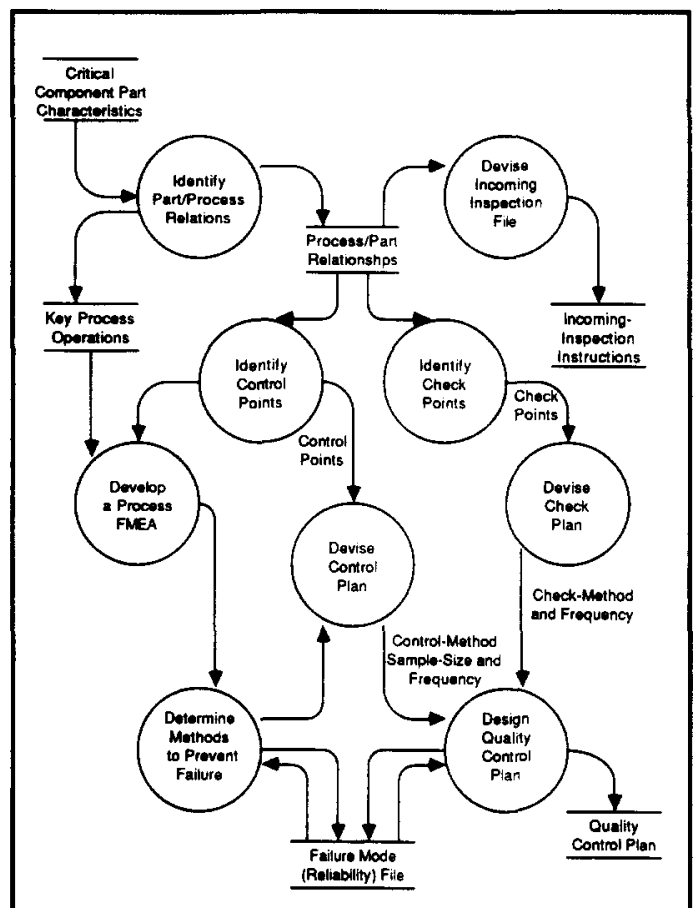

Figure 5 Process development \& quality control planning

\section{iv Production operation planning}

The generation of operating instructions for the plant is next achieved in the following stage of the deployment process. The quality control plan coming out of process planning is analyzed in order to identify three major production requirements: equipment and manpower plans, control items, and check methods.

The quality control plan, together with the process specifications for each component part, is analyzed to determine the appropriate equipment to use in each of the processes.
Once the equipment requirements have been specified, a method study is next performed on the necessary process elements in order to determine the optimum means of performing such operations using the given equipment. Operation methods and standards are thus generated by the study and are appropriately documented in standard methods file.

With the operation methods and standards known, a time study is performed to determine standard operating times for each of the requirement processes. These standard times are documented in a Time Standards File which is further used by manpower planning in determining plant manpower requirements. Manpower requirements include the required number and skills of personnel to perform the necessary processes on the specified equipment.

Control items and check methods are translated from the original control and check plans generated by process planning. Control and check procedures are specified and these include the appropriate control items, check methods, sampling sizes, and sampling frequencies for each and every component part and process. An overall production quality plan is designed with the operation methods and standards inputs from methods study. A final

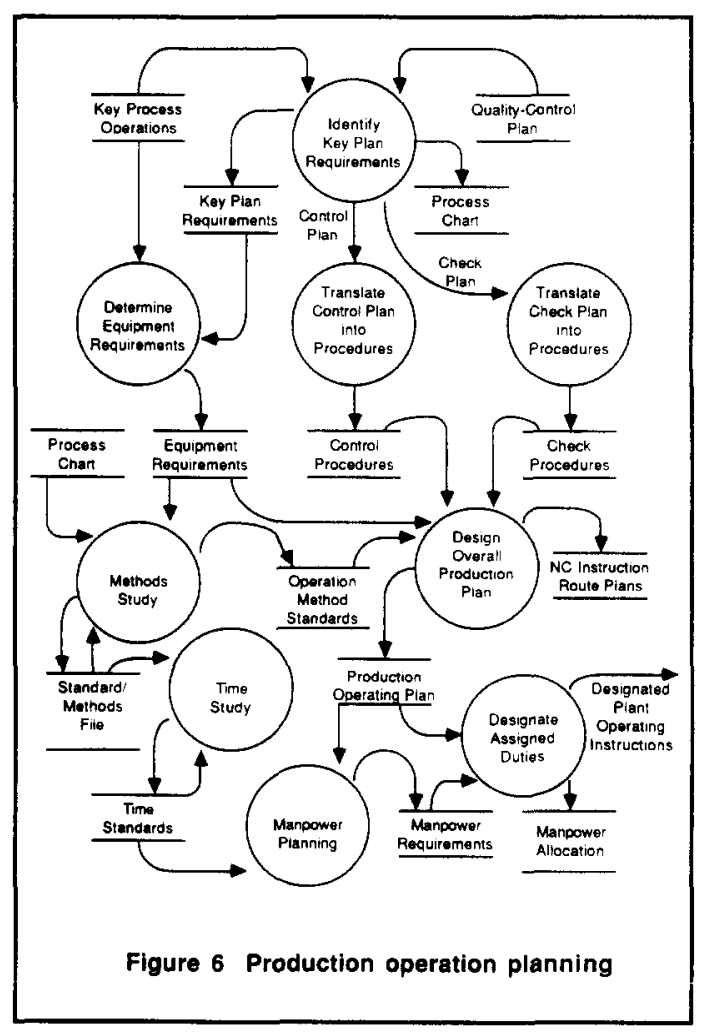


step would be to identify specific duties and responsibilities for every item in the consolidated operations plan based on the manpower requirements submitted by manpower planning. The expected outputs are specific plant operating instructions for every plant worker and/or machine designed to achieve the specific quality requirements and wants originally identified by the customers. The QFD process covers activities up to this point.

\section{v. Incoming inspection}

To protect the quality of the product from using defective parts, the preproduction quality function also enforces incoming inspection. It tests the incoming parts and makes sure that only quality parts will be sent to the production lines and/or warehouse. Vendor performance will be studied along with the incoming inspection process. Any acceptance or rejection will be recorded in the vendor-history files. The feedback from the production lines may also form the input to update the information about the vendor's performance.

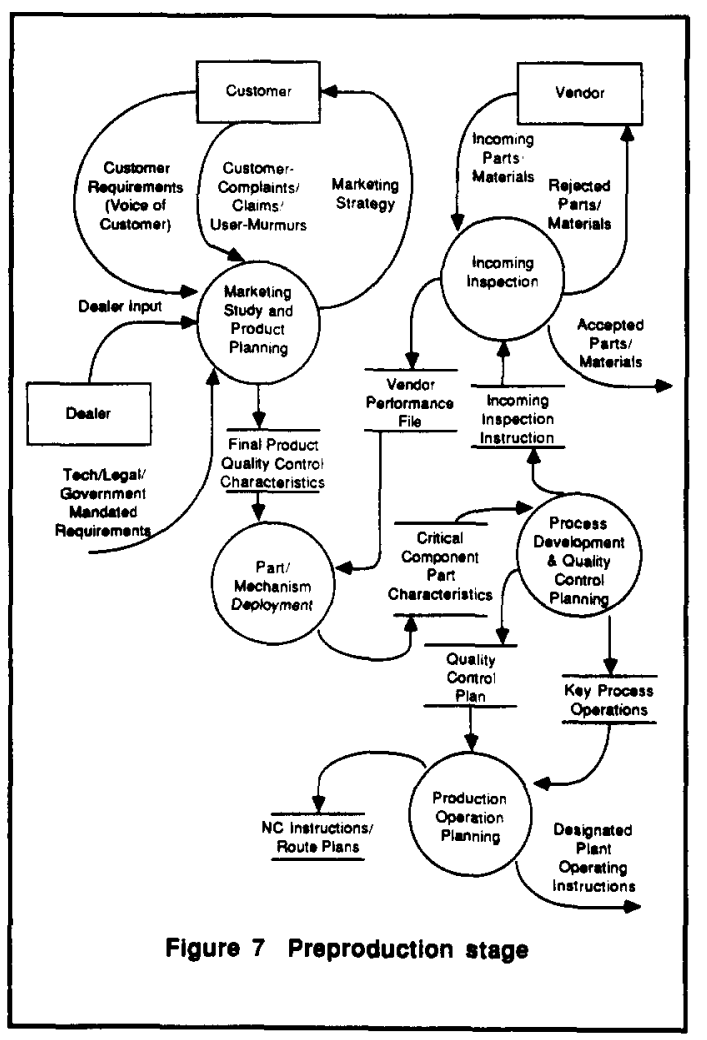

\section{Production Stage}

The quality control function during the production stage basically revolves around two mainstream quality functions: in-process inspection and statistical process control.
Manufacturing process feedback in terms of the inspection results and real time process data are reported to the quality information system and used as input to the statistical analysis of such data. In this activity, defects and defective parts and products are monitored such that they are kept to a minimum and below allowable levels.

Whereas in-process inspection is the data gathering phase, statistical process control is the "data analysis" aspect of the quality function in the production stage. In this activity, data gathered by in-process inspection is analyzed and charted for the early detection of out-of-control conditions as well as situations which can lead to or are already bound for such conditions. For out-of-control items, process alarms are generated for immediate notification of those concerned. Defects and their causes are also identified so that the appropriate corrective actions are initiated. A history of these process control data is maintained for future reference as well as for report generation and ad-hoc user queries.

\section{Postproduction Stage}

The quality control function extends up to after the product is manufactured and passes final inspection. Critical activities that affect final product quality are also identified in the physical distribution function. These include the careful packaging, warehousing, handling, and shipping of the finished goods to the customer. This ensures that delivered products reach the customer in the same conditions as when they were approved for shipment.

However, the quality function does not end there. After-sale service is just as important as delivering the product itself. An effective service and product warranty program is essential to sustain customer satisfaction with the product. Likewise, reports of field failures and user dissatisfaction are monitored, recorded, and analyzed. Sales returns and customer complaints are also recorded and immediately investigated. Failed products are sent to the reliability laboratories for testing and failure analysis. Failure causes are identified and reflected on new failure mode and effects analyses and on the basis of these investigations, corrective actions and/or necessary engineering changes are commended. This process leads back to the market research and product design activities of the preproduction stage and thus completes the quality information system life cycle for a customer-driven and customer-oriented company. 


\section{CONCLUSION}

The views of quality function have undergone dramatic changes during the recent years. The purpose of enforcing quality function has been extended from providing defect free products toward customer satisfaction. In order to produce customer desired products, marketing, product design, manufacturing process planning and control activities are tied into one integrated process called Quality Function Deployment.

A general design of an integrated total quality information system involving the Quality Function Deployment process is proposed in this paper. The idea that a company's planning and operations should be driven by the voice of customer broadened the traditional coverage of quality function. The phase of planning and design plays a much more important role under such a new idea. Data flow diagram is used to illustrate the structure of the information system. Within it, the Quality Function Deployment process is especially discussed in detail.

\section{ACKNOWLEDGEMENT}

The work described in this paper is supported by a grant from the Product Quality Research Center, the University of Michigan-Dearborn. The author also wishes to thank Eric Grajo for his assistance in the development of this article.

\section{REFERENCES}

[1] Fortuna, R. M., "Beyond Quality: Taking SPC Upstream," Quality Progress, June 1988

[2] Hauser, J. R. and D. Clausing, "The House of Quality," Harvard Business Review, May-June 1988

[3] Ishikawa, K., What Is Total Quality Control? The Japanese Way, Prentice-Hall Inc., Englewood Cliffs, 1985

[4] Joyner, J. M., "Marketing's Role In Quality Improvement," Quality Progress, June 1986

[5] Kogure, M. and Y. Akao, "Quality Function Deployment and CWQC in Japan," Quality Progress, October 1983

[6] Kukla, B., "Meeting Customer Needs," Quality Progress, June 1986

[7] McHugh, J. E., Quality Function Deployment, American Supplier Institute, Dearborn, 1986
[8] Plsek, P. E., "Defining Quality at the Marketing/Development Interface," Quality Progress, June 1987

[9] Sullivan, L. P., "Policy Management through Quality Function Deployment," Quality Progress, June 1988

[10] Sullivan, L. P., "Quality Function Deployment," Quality Progress, June 1986

[11] Suresh, N. C. and J. R. Meredith, "Quality Assurance Information Systems for Factory Automation," Int. J. of Production Research, Vol. 23, No. 3, 1985

[12] Takei, F., "Engineering Quality Improvement through TQC Activity," IEEE Transactions on Engineering Management, Vol. EM-33, No. 2, 1986

[13] Takeuchi, H. and J. A. Quelch, "Quality Is More than Making a Good Product," Harvard Business Review, July-August 1983

\section{BIOGRAPHICAL SKETCH}

Dr. Chia-hao Chang is an Associate Professor of Industrial and Systems Engineering at the University of Michigan-Dearborn. His current research interests include Computer Integrated Manufacturing Systems, Quality Information Systems Design, and Expert Systems. He is a senior member of IIE and SME, and also a member of ACM, IEEE-Computer Society, Sigma $\mathrm{Xi}$, Alpha Pi Mu and Upsilon Pi Epsilon. 